\title{
Correspondence
}

\section{An ode to clinical independence}

DeAR Sirs

A solicitor called to meet a client in custody, represents his interests the best way he can. Such an 'independent' legal representation is necessary because ethnic minorities and the mentally disordered sometimes get a raw deal in a legal system, that in controversial cases appears more interested in 'being seen to carry out a task' than necessarily doing that task as accurately as possible. For instance, the spate of recent appeals and quashings of sentences, as with the Guildford Four and the Blakelock killing, having established that there was absent or inadequate representation for the individuals concerned.

A potential conflict of interest between such independent legal representation and the legal system in the higher court forms the basis of the adversarial system. Here a Defence Counsel will present a case in opposition or in competition to the Crown's. Such a system arguably gives a defendant a chance to be better heard.

There are parallel issues in the medical world which are quite worrying. St Charles' Youth Treatment Centre was the subject of a recent enquiry, prompted by media disclosures of alleged mistreatment of one of its youngsters. One of the resultant recommendations is that management are intending to employ more psychologists, making them the primary clinicians. 'Medication' aspects will be dealt with by a visiting psychiatrist who will be expected only to monitor this aspect. How does this alter the quality of service for these youngsters?

One problem lies in the degree and relevance of clinical autonomy that is professionally possible within an environment where departmental or unit policies are followed, 'unrefracted' by independent clinical representation of the patient. Such line managed' clinicians serve the institution or State rather than represent their clients or patients. Clinical autonomy and responsibility is subsumed respectively by line management directives and managerial responsibility. Fundamental questions concerning the differences between treatment and clinical management are raised.

At St Charles' politically expedient directives can alter a psychotherapeutic and growth-enabling environment into a behaviourally-run organisation where the emphasis rests on care and control, probably because such organisations run more smoothly.
As stated above, unrepresented defendants have enabled a criminal justice service to appear to run more smoothly. Nowadays, Crown indemnity for NHS clinicians theoretically enables clinical responsibility (including that of doctors) to be subsumed by managerial responsibility, even though doctors, who are often at the final common pathway of service delivery, can attract manslaughter charges when organisational and training difficulties are felt to be relevant (Dyer, 1991).

Additionally, in the 'new' health service doctors are often criticised for speaking out and 'whingeing' but that is exactly what a good solicitor and a good Defence Counsel does sometimes against very many odds in a system that often is doing what the Government of the day or public opinion decrees. Recent newspaper accounts report doctors being threatened with dismissal for speaking 'out of turn'. The new Trusts no doubt, and understandably so, feel that it is appropriate and tidier to have a coordinated public face, but the loss of an independent clinical platform, whether in public or at the more private interface in the doctor/patient relationship, is threatened in the current climate. Confusing and threatening to some is the simplicity of the doctors' primary ethical 'beacon'-the Hippocratic Oath. From it a doctor derives his professional and patient credibility in order to work in the patient's best interests. Such clinical autonomy, a necessary prerequisite for treatment, seems to have a dwindling influence in the corporate world of health delivery today.

A good lawyer will, if necessary interrupt Court proceedings, seek adjournments, and vigorously disagree with the Court system - all in an attempt to best represent his client. His status as a criminal solicitor or Defence Counsel will rise according to his abilities. A doctor nowadays who questions, who tackles the system, who says "what of my patient though' is told that he is shroud waving or that he is awkward, and he can now be threatened with dismissal.

T.D. SCANNELL

\section{St Bartholomew's Hospital \\ West Smithfield \\ London EC1A 7BE}

\section{Reference}

DYER, C. (1991) Manslaughter conviction for making mistakes. British Medical Journal, 303, 1218. 